\title{
Maternal sociodemographic characteristics, early pregnancy behaviours, and livebirth outcomes as congenital heart defects risk factors - Northern Ireland 2010-2014
}

Hafi Saad ${ }^{1 *}$, Marlene Sinclair ${ }^{1}$ and Brendan Bunting ${ }^{2}$

\begin{abstract}
Background: Congenital Heart Defects (CHD) is the most commonly occurring congenital anomaly in Europe and a major paediatric health care concern. Investigations are needed to enable identification of CHD risk factors as studies have given conflicting results. This study aim was to identify maternal sociodemographic characteristics, behaviours, and birth outcomes as risk factors for CHD. This was a population based, data linkage cohort study using anonymised data from Northern Ireland (NI) covering the period 2010-2014. The study cohort composed of 94,067 live births with an outcome of 1162 cases of CHD using the International Statistical Classification of Diseases and Related Health Problems (ICD)-10 codes and based on the European Surveillance of Congenital Anomalies (EUROCAT) grouping system for CHD. CHD cases were obtained from the HeartSuite database (HSD) at the Royal Belfast Hospital for Sick Children (RBHSC), maternal data were extracted from the Northern Ireland Maternity System (NIMATS), and medication data were extracted from the Enhanced Prescribing Database (EPD). STATA version 14 was used for the statistical analysis in this study, Odds Ratio (OR), 95\% Confident intervals (Cl), P value, and logistic regression were used in the analysis. Ethical approval was granted from the National Health Service (NHS) Research Ethics Committee.
\end{abstract}

Result: In this study, a number of potential risk factors were assessed for statistically significant association with CHD, however only certain risk factors demonstrated a statistically significant association with CHD which included: gestational age at first booking $(A O R=1.21 ; 95 \% \mathrm{Cl}=1.04-1.41 ; \mathrm{P}<0.05)$, family history of $\mathrm{CHD}$ or congenital abnormalities and syndromes $(A O R=4.14 ; 95 \% C l=2.47-6.96 ; P<0.05)$, woman's smoking in pregnancy $(A O R=1.22 ; 95 \% C l=1.04$ $1.43 ; \mathrm{P}<0.05)$, preterm birth $(A O R=3.01 ; 95 \% \mathrm{Cl}=2.44-3.01 ; \mathrm{P}<0.05)$, multiple births $(A O R=1.89 ; 95 \% \mathrm{Cl}=1.58-2.60$; $P<0.05)$, history of abortion ( $A O R=1.12 ; 95 \% C l=1.03-1.28 ; P<0.05)$, small for gestational age (SGA) $(A O R=1.44$; $95 \% \mathrm{Cl}=1.22-1.78 ; \mathrm{P}<0.05)$, and low birth weight $(\mathrm{LBW})(\mathrm{AOR}=3.10 ; 95 \% \mathrm{Cl}=2.22-3.55 ; \mathrm{P}<0.05)$. Prescriptions and redemptions of antidiabetic $(A O R=2.68 ; 95 \% C l=1.85-3.98 ; \mathrm{P}<0.05)$, antiepileptic $(\mathrm{AOR}=1.77 ; 95 \% \mathrm{Cl}=1.10-2.81$; $\mathrm{P}<0.05)$, and dihydrofolate reductase inhibitors (DHFRI) $(A O R=2.13 ; 95 \% \mathrm{Cl}=1.17-5.85 ; \mathrm{P}<0.05)$ in early pregnancy also showed evidence of statistically significant association with CHD.

Conclusion: The results of this study suggested that there are certain maternal sociodemographic characteristics, behaviours and birth outcomes that are statistically significantly associated with higher risk of CHD. Appropriate

\footnotetext{
*Correspondence: Saad-h@ulster.ac.uk

${ }^{1}$ Maternal Fetal and Infant Research Centre, Ulster University,

Jordanstown, UK

Full list of author information is available at the end of the article
} original author(s) and the source, provide a link to the Creative Commons licence, and indicate if changes were made. The images or other third party material in this article are included in the article's Creative Commons licence, unless indicated otherwise in a credit line to the material. If material is not included in the article's Creative Commons licence and your intended use is not permitted by statutory regulation or exceeds the permitted use, you will need to obtain permission directly from the copyright holder. To view a copy of this licence, visit http://creativecommons.org/licenses/by/4.0/. The Creative Commons Public Domain Dedication waiver (http://creativeco mmons.org/publicdomain/zero/1.0/) applies to the data made available in this article, unless otherwise stated in a credit line to the data. 
prevention policy to target groups with higher risk for CHD may help to reduce CHD prevalence. These results are important for policy makers, obstetricians, cardiologists, paediatricians, midwives and the public.

Keywords: Congenital Heart Defects (CHD), Risk Factors, Population Based, Data Linkage, Cohort, Anonymised Data, Northern Ireland

\section{Introduction}

Congenital heart defects (CHD) is the most commonly occurring congenital anomaly in Europe [1], and one of the main concerns in paediatric health care which has a serious impact on infant mortality rates worldwide [2-4]. CHD impacts on health services as well as patients and their families [5-7], it represents a major global health problem and efforts should be continued to decrease the burden of the disease and to offer advice where possible, on reduction of risks of $\mathrm{CHD}$.

Identifying the risk factors for $\mathrm{CHD}$ is of importance as intervening in relation to a particular risk may lead to prevention of CHD. Studies have been undertaken in the field of CHD risk factor research but have shown conflicting results [8]. Therefore, additional investigations are needed to enable accurate and robust identification of CHD risk factors [9] and to ensure that the required interventions are targeted more appropriately.

This study aimed to explore the impact of maternal sociodemographic characteristics and lifestyle behaviours as risk factors for CHD in Northern Ireland (NI) and to contribute to the current evidence on CHD to inform public health and social care policy.

$\mathrm{NI}$ is ideal for studying the risk factors for CHD as there is a single centre for foetal and paediatric cardiology in the Royal Belfast Hospital for Sick Children (RBHSC), and all children in NI with CHD are first seen at this centre. Administrative and clinical records of all pregnant women in NI and General Practitioner (GP) prescribing data are available centrally through the Honest Broker Service (HBS) [10] for (Health and Social Care) HSC sector in NI.

\section{Methodology}

\section{Study design}

This was a population-based cohort study based on secondary data analysis of linked datasets from HeartSuite Database (HSD), Northern Ireland Maternity System (NIMATS), and Enhanced Prescribing Database (EPD) (These datasets are described in another paper [11]).

\section{Study population and period}

The study population includes all live births registered to women residing in NI during the period 2010-2014.

\section{Dataset description}

For maternal sociodemographic characteristics and behaviours; risk factors were collected from details of the first booking visit from NIMATS database $(92 \%$ of women gave this information in week 14 or less). Of the 96,233 pregnancies, 94,804 gave birth to cases without CHD (98.52\%), and 1429 gave birth to CHD cases (1.48\%). The births were to NI resident women, based on NI postcode and registered in the original NIMATS. For multiple pregnancies, only the baby with CHD was included; if there was no baby with CHD, only the most recent pregnancy was included, except where a mother had more than one baby with CHD, in which case both pregnancies were included, and except in the case of multiple births, when all were included.

Data from HSD: the CHD cases are major CHD cases recorded in HSD file based on EUROCAT grouping [12] using ICD10 codes containing a value between Q20.0 and Q26.9, except for Q25.0, Q25.6, or Q26. The sample includes only NI resident babies.

Medications prescribed and redeemed were obtained from EPD: an extract from the EPD, which contains detailed information in relation to NI prescriptions issued in primary care and redeemed by patients (based on British National Formulary (BNF) classification) was prepared by the HBS. This extract only includes data for NI-resident women registered in NIMATS for the period 2010-2014 and is only specific to each woman's Exposure Window (EW), where EW= date of Last Menstrual Period (LMP) - 30 days and date of LMP + 90 days, using the date of each medication prescription. The EW begins 30 days prior to the first day of the woman's LMP to enable medication prescriptions taken immediately before conception and possibly taken in early pregnancy to be included. This timing has been used in the design of other studies researching medication transfer in pregnancy [13-16].

The aetiology of CHD is apparent among babies with chromosomal and genetic syndromes, and among pregnant woman who are using vitamin A, anti-diabetic, or anti-epileptic medication, therefore these cases were excluded in the final file for analysis. This helps to increase the sensitivity of this study to assess the association with the other risk factors. However, before exclusion the associations between anti-diabetic or anti-epileptic medication and CHD were assessed. 222 


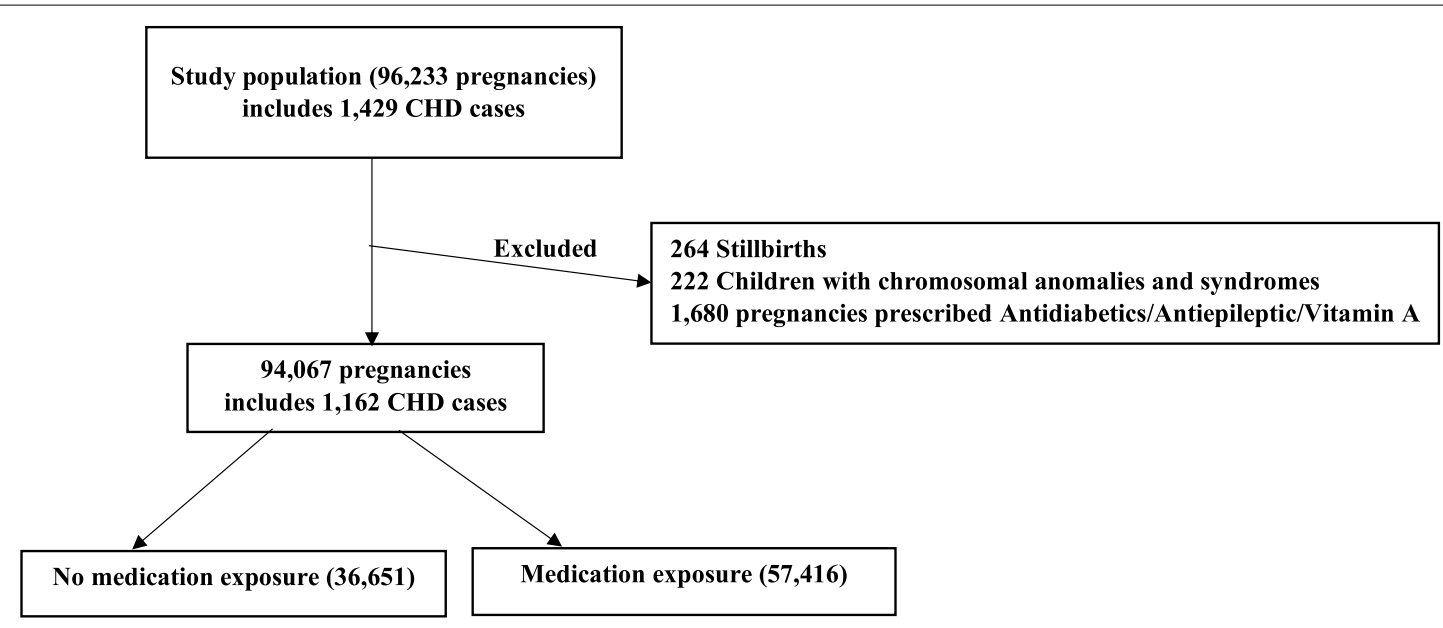

Risk factors assessed in this study:

- Gestational age at first booking

- Rurallurban residency

- Deprivation based on NIMDM

- Woman's age at first booking

- Parity

- History of abortion (whether spontaneous or induced)

- History of CHD or congenital abnormalities and syndromes

- BMI

- Smoking
- Medications exposure (self reported)

- Medications exposure (prescriptions and redemptions)

- Unplanned pregnancy

- Term\preterm

- Multiple birth

- SGA

- LBW

- Gender

- Alcohol consumption

Fig. 1 Flow of the data in the study population Nl during the period 2010-2014, including risk factors assessed in the study. CHD=Congenital Heart Defects, BMI=Body Mass Index, SGA=Small for Gestational Age, LBW=Low Birth Weight, NIMDM= Northern Ireland Multiple Deprivation Measures

chromosomal and genetic syndromes were excluded according to the following ICD10 codes Q90.0-Q93.0, Q96.0-Q99.9, Q44.71, Q61.90, Q74.84, Q75.1, Q75.4, Q75.81, Q87, Q93.6, and D82.1.

Another 1680 cases in which the pregnant woman redeemed a prescription for vitamin $\mathrm{A}$, anti-diabetic, or anti-epileptic medication were excluded. The exclusions were based on BNF sections. Section 9.6.1 for vitamin A, sections 6.1.1 and 6.1.2 for anti-diabetic, and section 4.8 for anti-epileptic medication (https://openprescribing. net/bnf/). As the cause of stillbirth was not known in this study, 264 pregnancies which resulted in stillbirths were excluded.

The final file therefore includes 94,067 pregnancies including 1162 CHD cases. The flow of data is shown in Fig. 1.

\section{Data linkage}

During the study period there were 1605 CHD cases in HSD file and of these, 1429 CHD cases were able to be linked to NIMATS (HSD file contains only CHD cases, mothers in NIMATS which are not linked to HSD are assumed to be mothers of cases with no CHD) by HBS through deterministic linking using the infant Health and Care Numbers (INFANT_HCN). In the EPD extract there were 59,406 pregnancies which were linked successfully by the author (H.S.) to the NIMATS/HSD file using a common identifier (study_id) for both files.

\section{Statistical analysis}

Odds Ratio (OR) with 95\% confidence interval (CI) and $P$ value were used as the association between exposure to specific risk factor and the CHD. Another frequently used measure of association reported in literature when publishing cohort study is risk ratio (RR) $[17,18]$. Where outcomes are rare, as in the current case (typically $<10 \%$ ) the values associated with OR and RR are similar $[19,20]$. As there is a binary outcome of interest (CHD or not) and a number of explanatory covariates (risk factors), logistic regression was used. To account for the possible clustering effects of multiple births, this covariate was included within the analysis. 
The analysis was only performed when there were at least $3 \mathrm{CHD}$ cases occurring after exposure or lack of exposure for each potential risk factor. Bivariate and multivariable analysis model parameters were estimated using maximum likelihood in STATA version 14.

\section{Missing data}

Complete subject analysis was adopted and subjects with missing data in any potential risks were excluded from the analysis. The multivariable model is based on 90,079 pregnancies out of 94,067 pregnancies in the final file (approximately 96\%). No imputation was conducted in this study and all percentages of missing values for each potential risk were presented.

\section{Covariates in the study}

Those which have been examined for evidence of statistically significant association with CHD are gestational age at first booking, rural residency, pregnancy deprivation using Northern Ireland Multiple Deprivation Measures (NIMDM), woman's age at booking, parity, family history of CHD or congenital abnormalities and syndromes, preterm birth, multiple births, history of abortion (whether spontaneous or induced), small for gestational age (SGA), low birth weight (LBW) (birth weight $<2500 \mathrm{~g}$ ), gender, unplanned pregnancy, woman's Body Mass Index (BMI), woman's alcohol consumption, woman's smoking in pregnancy, woman's self-reported usage of folic acid (FA) and vitamins or any other group of medications, prescriptions and redemptions of FA and vitamin, mental health medication (MHM), and other medications.

\section{Results}

Table 1 shows the association between the 18 potential risk factors assessed in this study and CHD using OR, 95\% CI, and P value. Women who booked their first antenatal appointment after 14 weeks of pregnancy had an increased risk of their offspring developing CHD $(P=0.01)$. Family history of CHD or history of CHD and congenital abnormalities and syndromes showed strong evidence of statistically significant positive association with $\mathrm{CHD}(\mathrm{P}<0.01)$. The positive association with $\mathrm{CHD}$ also increased significantly in pregnant women who smoked $(\mathrm{P}<0.05)$.

Women's usage of medications in pregnancy (based on self-reported data taken from NIMATS), showed that taking other medications (other medications in NIMATS are any medication except FA and vitamins) had statistically positive association with CHD $(\mathrm{P}<0.05)$. Medications from EPD are categorised into non-medication, FA and vitamin, dihydrofolate reductase inhibitors (DHFRI), MHM, and other medications (other medications in EPD are any medication that is not FA, DHFRI, or MHM). Using the EPD file showed that prescription and redemption of MHM has no significant association with CHD $(\mathrm{P}=0.40)$. In contrast, DHFRI have shown a significantly increased risk of developing CHD $(\mathrm{P}<0.05)$. However, FA supplement alone showed no significant protective association with CHD (P > 0.05).

Before excluding pregnancies which were exposed to antidiabetic and antiepileptic medications, their association with CHD was assessed, and both antidiabetic and antiepileptic medications showed statistically significant association with $\mathrm{CHD}$ with $(\mathrm{AOR}=2.68$; 95\% $\mathrm{CI}=1.85$ $3.98 ; \mathrm{P}<0.01)$ and $(\mathrm{AOR}=1.77 ; 95 \% \mathrm{CI}=1.10-2.81$; $\mathrm{P}<0.02)$, respectively.

Other potential risk factors related to the baby were examined, and data showed evidence of positive association with CHD and preterm birth $(\mathrm{P}<0.01)$, LBW (birth weight $<2500 \mathrm{~g})(\mathrm{P}<0.01)$, SGA $(\mathrm{P}<0.01)$, and multiple births $(\mathrm{P}<0.01)$. There was strong evidence of a positive association between. history of abortion and CHD $(\mathrm{P}<0.05)$.

\section{Discussion}

Women who booked their first antenatal appointment after 14weeks of pregnancy had an increased risk of their offspring developing $\mathrm{CHD}$, this may be because provision of antenatal care (ANC) before 14 weeks allows guidance to be provided at an early stage on modifiable lifestyle risks such as smoking, alcohol consumption and using certain teratogens. Early ANC also captures DM and could enhance blood glycaemic control. It is therefore crucial for ensuring optimal care and good maternal and foetal health [21]. Late booking (which delays ANC) may delay dealing with the risks outlined above, most of which have shown an increased association with CHD in offspring. The study suggests that health service planning should investigate the reasons behind late first booking appointments and ensure a policy to reduce these due to the association with CHD and other potential adverse outcomes for both babies and pregnancies.

There was no higher risk of developing CHD among infants whose mothers lived in rural areas in comparison to urban areas. The literature showed conflicting results regarding the association between rural or urban residency and CHD in offspring [22, 23]. Being categorised in the most deprived group based on NIMDM as a proxy of SES was not shown to have a statistically significant association with CHD. And there is no evidence that differences in SES (based on area level measures) affect the occurrence of CHD in NI. However, the findings of this study may be consistent with a finding from 
Table 1 Association between potential risk factors and CHD in NI (2010-2014) using OR, 95\% Cl, and P value (bivariate/multivariable analysis)

\begin{tabular}{|c|c|c|c|c|c|c|c|c|}
\hline Covariate & No CHD & CHD & Total & $\%$ from total & $\begin{array}{l}\text { Crude } \\
\text { OR } 95 \% \mathrm{Cl}\end{array}$ & P value & $\begin{array}{l}\text { Adjusted } \\
\mathrm{OR}^{*} 95 \% \mathrm{Cl}\end{array}$ & $P$ value \\
\hline \multicolumn{9}{|l|}{ 1. Gestational age at first booking } \\
\hline$\leq 14$ weeks & 85,126 & 1043 & 86,169 & 92 & & & & \\
\hline$>14$ weeks & 7779 & 119 & 7898 & 8 & $1.25(1.03-1.51)$ & 0.02 & $1.21(1.04-1.41)$ & 0.01 \\
\hline Missing & 0 & 0 & 0 & 0 & & & & \\
\hline Total & 92,905 & 1162 & 94,067 & 100 & & & & \\
\hline \multicolumn{9}{|l|}{ 2. Rural residency } \\
\hline Urban & 59,637 & 746 & 60,383 & 64.19 & & & & \\
\hline Rural & 31,999 & 414 & 32,413 & 34.46 & $1.03(0.92-1.17)$ & 0.58 & $1.04(0.92-1.18)$ & 0.52 \\
\hline Missing & $\#$ & $\#$ & 1271 & 1.35 & & & & \\
\hline Total & $\#$ & \# & 94,067 & 100 & & & & \\
\hline \multicolumn{9}{|l|}{ 3. Deprivation using NIMDM2010 } \\
\hline Quintile 5 (Least deprived) & 14,167 & 180 & 14,347 & 15.25 & & & & \\
\hline Quintile 4 & 17,880 & 218 & 18,098 & 19.24 & $0.96(0.79-1.17)$ & 0.68 & $0.94(0.77-1.15)$ & 0.56 \\
\hline Quintile 3 & 18,971 & 259 & 19,230 & 20.44 & $1.07(0.89-1.30)$ & 0.46 & $1.03(0.84-1.25)$ & 0.38 \\
\hline Quintile 2 & 19,529 & 225 & 19,754 & 21.0 & $0.91(0.74-1.10)$ & 0.33 & $0.86(0.70-1.05)$ & 0.14 \\
\hline Quintile 1 (Most deprived) & 21,157 & 279 & 21,436 & 22.79 & $1.04(0.86-1.25)$ & 0.70 & $0.97(0.80-1.19)$ & 0.58 \\
\hline Missing & $\#$ & \# & 1202 & 1.28 & & & & \\
\hline Total & $\#$ & $\#$ & 94,067 & & & & & \\
\hline \multicolumn{9}{|l|}{ 4. Parity } \\
\hline PO (Nulliparous) & 33,071 & 469 & 33,540 & 35.66 & & & & \\
\hline P1 & 33,852 & 403 & 34,255 & 36.42 & $0.84(0.73-0.96)$ & 0.01 & $0.77(0.70-0.88)$ & 0.01 \\
\hline P2 & 16,888 & 173 & 17,061 & 18.14 & $0.72(0.61-0.86)$ & $<0.01$ & $0.69(0.59-0.79)$ & $<0.01$ \\
\hline P3 & 5932 & 64 & 5996 & 6.37 & $0.76(0.59-0.99)$ & 0.04 & $0.75(0.57-0.99)$ & 0.04 \\
\hline P4 & 1764 & 28 & 1792 & 1.91 & $1.12(0.76-1.64)$ & 0.57 & $1.01(0.71-1.44)$ & 0.41 \\
\hline$\geq$ P5 (Grand multipara) & 970 & 17 & 987 & 1.05 & $1.24(0.76-2.01)$ & 0.39 & $1.24(0.76-2.01)$ & 0.39 \\
\hline Missing & $\#$ & $\#$ & 436 & 0.46 & & & & \\
\hline Total & $\#$ & $\#$ & 94,067 & & & & & \\
\hline \multicolumn{9}{|l|}{ 5. Woman's age at first booking } \\
\hline 25-29years & 25,968 & 342 & 26,310 & 27.97 & & & & \\
\hline 20-24years & 14,863 & 167 & 15,030 & 15.98 & $0.85(0.71-1.32)$ & 0.09 & $0.80(0.66-0.98)$ & 0.05 \\
\hline 30-34year & 28,919 & 370 & 29,289 & 31.14 & $0.97(0.84-1.13)$ & 0.70 & $0.98(0.85-1.15)$ & 0.69 \\
\hline 35-39years & 15,280 & 186 & 15,466 & 16.44 & $0.92(0.77-1.11)$ & 0.39 & $0.90(0.75-1.09)$ & 0.27 \\
\hline $40+$ years & 3091 & 36 & 3127 & 3.32 & $0.88(0.63-1.25)$ & 0.49 & $0.84(0.59-1.21)$ & 0.36 \\
\hline$<20$ years & 4738 & 58 & 4796 & 5.10 & $0.93(0.70-1.23)$ & 0.61 & $0.87(0.64-1.17)$ & 0.35 \\
\hline Missing & $\#$ & $\#$ & 49 & 0.05 & & & & \\
\hline Total & $\#$ & $\#$ & 94,067 & & & & & \\
\hline \multicolumn{9}{|c|}{ 6. History of CHD or congenital abnormalities and syndromes } \\
\hline $\begin{array}{l}\text { No history of CHD or congenital abnormalities and } \\
\text { syndromes }\end{array}$ & 81,641 & 841 & 82,482 & 87.68 & & & & \\
\hline Only history of CHD & 6310 & 237 & 6547 & 6.96 & $3.65(3.15-4.22)$ & $<0.01$ & $3.62(3.11-4.21)$ & $<0.01$ \\
\hline $\begin{array}{l}\text { Only history of congenital abnormalities and syn- } \\
\text { dromes }\end{array}$ & 4593 & 68 & 4661 & 4.95 & $1.44(1.12-1.84)$ & $<0.01$ & $1.28(0.99-1.67)$ & 0.05 \\
\hline $\begin{array}{l}\text { History of CHD and congenital abnormalities and } \\
\text { syndromes }\end{array}$ & 361 & 16 & 377 & 0.40 & $4.3(2.60-7.13)$ & $<0.01$ & $4.14(2.47-6.96)$ & $<0.01$ \\
\hline Missing & 0 & 0 & 0 & 0 & & & & \\
\hline Total & 92,905 & 1162 & 94,067 & & & & & \\
\hline \multicolumn{9}{|l|}{ 7. Woman's smoking in pregnancy } \\
\hline No smoking & 77,453 & 933 & 78,386 & 83.33 & & & & \\
\hline Smoking & 15,383 & 228 & 15,611 & 16.60 & $1.23(1.06-1.42)$ & $<0.01$ & $1.22(1.04-1.43)$ & 0.02 \\
\hline
\end{tabular}


Table 1 (continued)

\begin{tabular}{|c|c|c|c|c|c|c|c|c|}
\hline Covariate & No CHD & CHD & Total & $\%$ from total & $\begin{array}{l}\text { Crude } \\
\text { OR 95\% Cl }\end{array}$ & P value & $\begin{array}{l}\text { Adjusted } \\
\mathrm{OR}^{*} 95 \% \mathrm{Cl}\end{array}$ & $P$ value \\
\hline Missing & $\#$ & \# & 70 & 0.07 & & & & \\
\hline Total & $\#$ & $\#$ & 94,067 & & & & & \\
\hline \multicolumn{9}{|l|}{ 8. Alcohol consumption } \\
\hline No alcohol consumption & 91,910 & 1149 & 93,059 & 98.93 & & & & \\
\hline Alcohol consumption & 914 & 12 & 926 & 0.98 & $1.05(0.59-1.86)$ & 0.87 & $0.96(0.53-1.76)$ & 0.81 \\
\hline Missing & $\#$ & \# & 82 & 0.09 & & & & \\
\hline Total & $\#$ & $\#$ & 94,067 & & & & & \\
\hline \multicolumn{9}{|l|}{ 9. Woman's BMI } \\
\hline Normal & 44,395 & 541 & 44,936 & 47.77 & & & & \\
\hline Overweight & 26,041 & 329 & 26,370 & 28.03 & $1.04(0.90-1.19)$ & 0.61 & $1.04(0.79-1.10)$ & 0.59 \\
\hline Obese & 15,027 & 186 & 15,213 & 16.17 & $1.02(0.86-1.20)$ & 0.86 & $1.01(0.71-1.01)$ & 0.73 \\
\hline Morbidly obese & 1924 & 22 & 1946 & 2.07 & $0.94(0.61-1.44)$ & 0.77 & $0.77(0.33-1.45)$ & 0.59 \\
\hline Underweight & 2033 & 31 & 2064 & 2.19 & $1.25(0.87-1.80)$ & 0.23 & $1.17(0.69-1.55)$ & 0.19 \\
\hline Missing & 3485 & 53 & 3538 & 3.76 & & & & \\
\hline Total & 92,905 & 1162 & 94,067 & & & & & \\
\hline \multicolumn{9}{|l|}{ 10. Unplanned pregnancy } \\
\hline Planned & 63,938 & 792 & 64,730 & 68.81 & & & & \\
\hline Unplanned & 26,535 & 330 & 26,865 & 28.56 & $1.00(0.88-1.14)$ & 0.95 & $1.01(0.87-1.18)$ & 0.87 \\
\hline Missing & 2432 & 40 & 2472 & 2.63 & & & & \\
\hline Total & 92,905 & 1162 & 94,067 & & & & & \\
\hline \multicolumn{9}{|c|}{ 11. Woman's self-reported usage of medication } \\
\hline None & 5103 & 51 & 5154 & 5.48 & & & & \\
\hline FA and vitamins & 68,878 & 849 & 69,727 & 74.12 & $1.23(0.93-1.64)$ & 0.15 & $1.11(0.85-1.55)$ & 0.13 \\
\hline Other medications** & 18,924 & 262 & 19,189 & 20.40 & $1.39(1.02-1.87)$ & 0.03 & $1.14(1.01-1.66)$ & 0.02 \\
\hline Missing & 0 & 0 & 0 & 0 & & & & \\
\hline Total & 92,905 & 1162 & 94,067 & & & & & \\
\hline \multicolumn{9}{|c|}{ 12. Prescriptions and redemptions of medications in EPD } \\
\hline No redemptions & 36,195 & 456 & 36,651 & 38.96 & & & & \\
\hline FA and Vitamin & 9883 & 120 & 10,003 & 10.63 & $0.96(0.79-1.18)$ & 0.72 & $0.89(0.77-1.18)$ & 0.61 \\
\hline DHFRI & \# & \# & $\#$ & $\#$ & $2.56(1.13-5.80)$ & 0.02 & $2.13(1.17-5.85)$ & 0.01 \\
\hline MHM & 6873 & 103 & 6976 & 7.42 & $1.19(0.96-1.48)$ & 0.11 & $1.33(0.87-1.68)$ & 0.10 \\
\hline Other medications*** & \# & \# & $\#$ & $\#$ & $0.95(0.84-1.09)$ & 0.52 & $0.98(0.77-1.18)$ & 0.42 \\
\hline Missing & 0 & 0 & 0 & 0 & & & & \\
\hline Total & 92,905 & 1162 & 94,067 & & & & & \\
\hline \multicolumn{9}{|l|}{ 13. Preterm birth } \\
\hline$\geq 37$ weeks (Term) & 86,240 & 943 & 87,183 & 92.68 & & & & \\
\hline$<37$ weeks (Preterm) & 6587 & 218 & 6805 & 7.23 & $3.03(2.61-3.51)$ & $<0.01$ & $3.01(2.44-3.01)$ & $<0.01$ \\
\hline Missing & $\#$ & \# & 79 & 0.08 & & & & \\
\hline Total & \# & \# & 94,067 & & & & & \\
\hline \multicolumn{9}{|l|}{ 14. Multiple birth } \\
\hline Single birth & 89,732 & 1085 & 90,817 & 96.55 & & & & \\
\hline Multiple birth & 3173 & 77 & 3250 & 3.45 & $2.01(1.59-2.54)$ & $<0.01$ & $1.89(1.58-2.60)$ & $<0.01$ \\
\hline Missing & 0 & 0 & 0 & & & & & \\
\hline Total & 92,905 & 1162 & 94,067 & & & & & \\
\hline \multicolumn{9}{|c|}{ 15. History of previous miscarriage or termination of pregnancy } \\
\hline No history of abortion & 67,230 & 803 & 68,033 & 72.32 & & & & \\
\hline History of abortion & 25,247 & 351 & 25,598 & 27.21 & $1.16(1.03-1.32)$ & 0.02 & $1.12(1.03-1.28)$ & 0.02 \\
\hline Missing & $\#$ & \# & 436 & 0.46 & & & & \\
\hline Total & \# & \# & 94,067 & & & & & \\
\hline
\end{tabular}


Table 1 (continued)

\begin{tabular}{|c|c|c|c|c|c|c|c|c|}
\hline Covariate & No CHD & CHD & Total & $\%$ from total & $\begin{array}{l}\text { Crude } \\
\text { OR 95\% CI }\end{array}$ & $P$ value & $\begin{array}{l}\text { Adjusted } \\
\mathrm{OR}^{*} 95 \% \mathrm{Cl}\end{array}$ & $P$ value \\
\hline \multicolumn{9}{|l|}{ 16. SGA } \\
\hline No SGA & 83,513 & 991 & 84,504 & 89.83 & & & & \\
\hline SGA & 8964 & 163 & 9127 & 9.70 & $1.53(1.30-1.81)$ & $<0.01$ & $1.44(1.22-1.78)$ & $<0.01$ \\
\hline Missing & $\#$ & \# & 436 & 0.46 & & & & \\
\hline Total & $\#$ & \# & 94,067 & & & & & \\
\hline \multicolumn{9}{|c|}{ 17. Low birth weight $(<2500 \mathrm{~g})$} \\
\hline No low birth weight & 87,552 & 971 & 88,523 & 94.11 & & & & \\
\hline Low birth weight & 3684 & 134 & 3818 & 4.06 & $3.28(2.73-3.94)$ & $<0.01$ & $3.1(2.22-3.55)$ & $<0.01$ \\
\hline Missing & 1669 & 57 & 1726 & 1.83 & & & & \\
\hline Total & 92,905 & 1162 & 94,067 & & & & & \\
\hline \multicolumn{9}{|l|}{ 18. Gender } \\
\hline Male & 47,460 & 609 & 48,069 & 51.10 & & & & \\
\hline Female & 45,427 & 553 & 45,980 & 48.88 & $0.95(0.84-1.07)$ & 0.37 & $0.89(0.67-1.12)$ & 0.32 \\
\hline Missing & 18 & 0 & 18 & 0.02 & & & & \\
\hline Total & 92,905 & 1162 & 94,067 & & & & & \\
\hline
\end{tabular}

\# Disclosure control by the researcher for numbers less than 10, as per the process laid out by HBS

SGA small for gestational age, MHM mental health medication, FA folic acid, DHFRI Di hydro folate reductase inhibitors

*Adjusted OR for gestational age at first booking, urban/rural residency, deprivation using NIMDM, parity, woman's age at first booking, unplanned pregnancy, history of CHD or congenital abnormalities and syndromes, woman's BMI, woman's smoking, alcohol consumption, woman's self-reported usage of medication, preterm baby, multiple birth, prescription and redemption of medication, history of abortion, SGA, LBW, and gender

**other medications in NIMATS are any medication except FA and vitamins

***other medications in EPD are any medication that is not FA, DHFRI, or MHM

The multivariable model is based on 90,079 pregnancies out of 94,067 pregnancies in the final file (approximately $96 \%$ )

a meta-analysis, which showed no clear relationship between SES and CHD in developed countries [24].

Parity was not shown to have a statistically significant association with CHD, meta-analysis showed no statistically significant association between parity (comparing highest to lowest) and CHD in studies conducted after 2010 [25] and this is consistent with the findings of this study.

Regarding the woman's age at first booking, no statistically significant association was shown between older women ( $>40$ years) and CHD. These results are challenging as they do not support earlier research [26, 27]. However, they do support more recent research reporting a lack of positive association between CHD and advanced age [28]. This data may alleviate anxiety amongst older mothers and reduce the number of referrals for early echocardiography to detect CHD that are primarily based on older age. It may also reassure older women that their age in itself does not confer additional risk of CHD, and it may support the belief that women in this age group take extra care during their pregnancy to protect their baby [28].

There was evidence in this study of a statistically significant positive association between maternal smoking and CHD. This finding suggests that population-based prevention strategies targeting smoking cessation in pregnancy should highlight this message. A decrease in maternal smoking during pregnancy could result in decreased risk of CHD. The positive association of maternal smoking with CHD found in this study is consistent with findings from National Birth Defects Prevention Study (NBDPS) [29]. The NBDPS database identified an increased risk of developing specific subtypes of CHD in offspring of pregnant women who smoked [29], and a meta-analysis showed a positive association between maternal smoking during pregnancy and risk of CHD [30]. The mechanisms through which smoking may cause CHD are still to be clearly identified. It has been postulated that maternal smoking has harmful effects on the development of the foetus; carbon monoxide and nicotine induce hypoxia and reduce the supply of essential nutrients to the embryo [31, 32]. Additionally, common components of cigarette smoke such as polycyclic aromatic hydrocarbons are suspected teratogens in laboratory tests on humans and animals [33, 34]. From a public health policy perspective, finding from this study and others may fuel the need to ring-fence funding for smoking cessation prenatally and antenatally. 
No statistically significant association with CHD was shown for alcohol consumption in this study. While this result is important it should not be interpreted as evidence that maternal drinking is safe, as it is known that prenatal exposure to low levels of alcohol, such as a single unit, can result in foetal alcohol syndrome (FAS) [35]. Nevertheless, no significant association between alcohol consumption in pregnancy and CHD was found in two recent meta-studies with a large sample size; these findings are consistent with those of the current study [36, 37].

Previous meta-analysis demonstrated that offspring of women with a history of abortion (whether spontaneous or induced) had a higher risk of developing CHD [38], a finding which was repeated in this study. While the specific biological mechanism which underlies the link between a history of previous abortion and the risk of CHD is still unclear, it has been suggested that history of abortion can cause mental stress to mothers [39], and literature $[40,41]$ found that mothers who were exposed to stress during pregnancy might have an increased risk of CHD in their offspring.

Family history of CHD or congenital abnormalities and syndromes is associated with increased risk of CHD. This finding has relevance for any preventative policy for $\mathrm{CHD}$, such as pre-conceptional counselling for parents with a family history of CHD. Midwives routinely collect this data and identify risk factors for congenital anomalies. However, evidence from literature and this study may lead to clinical policy developments resulting in more screening referrals for foetal cardiology at booking and more midwifery input to counselling mothers prior to tests. The positive association of family history of CHD or congenital abnormalities and syndromes and CHD found in this study is consistent with those of other studies in Denmark, Canada, and USA [42, 43].

The study has shown statistically positive association between CHD and prescription and redemption of FA antagonists group of medications (including antiepileptic and DHFRI) in early pregnancy. Clinicians in particular will be interested in this result as it may help to guide their prescription practice and midwives booking mothers into the antenatal clinic need to be alerted to this risk factor. This result is consistent with the findings from previous studies that assessed the association between FA antagonists and CHD, which showed that usage of FA antagonists (either DHFRI or antiepileptic) to be associated with an increased risk of CHD [44-46].

The pharmacological plausibility of this positive association confirms the importance of this finding at public health policy level. Impaired folate metabolism has been found to affect cardiac neural crest cell formation and migration and it has been suggested that this might interfere with heart development [47-50]. Impaired FA transport has led to extensive death of apoptotic cells in the developing heart [51].

Unplanned pregnancy has been shown to have no significant positive association with CHD. This is an important finding, as there is a scarcity of studies that address this question. It should be noted, however, that unplanned pregnancy may be more likely to be associated with certain behaviour in early pregnancy such as smoking, lower educational attainment [52], and outcomes such as preterm labour [53], all of which are associated with a higher risk of CHD.

FA supplementation showed no protective effect for CHD. This finding, which is based on data from two different sources (NIMATS and EPD), is surprising as most previous research has shown a protective effect for FA [54] and there is a plausible biological mechanism to justify this protective effect. This finding may call into question any policy which aims to reduce $\mathrm{CHD}$ prevalence by imposing population based folic acid fortification in NI. However, this lack of protective effect should be received with caution; as suggested by Hobbs et al. [55], the absence of a protective association between FA and CHD cannot be asserted without further analysis of relevant environmental and genetic factors. Furthermore, the finding that FA antagonists (DHFRI and antiepileptics) are associated with increased risk of CHD may also indicate the importance of FA in CHD causation. The finding that FA had no protective effect also could be due to the misclassification of exposure, in that the level of FA required for individuals had already been attained; molecular techniques are needed to test this theory. However, it is possible that the finding could reflect a true absence of protective effect, as in fact has been shown by a number of studies that have found no significant protective effect of FA supplementation on CHD [56, 57].

This study showed no statistically significant association between maternal obesity and risk of CHD. However, it must be noted that this finding conflicts with previous literature in which obese pregnant women were found to have a significantly increased risk of CHD [5860]. It is important to note that the mechanisms which explain the relationship between maternal obesity and CHD are unclear, although there is an argument that women who are obese may have Diabetes Mellitus (DM), which is a known risk factor for CHD [61]. The findings of this study support this argument as all DM cases were excluded from the analysis allowing the independent assessment of obesity as a risk factor for CHD.

In this study, certain factors are categorised as factors related to the child birth outcome, these were: SGA; multiple births; LBW; whether term or preterm; and gender. It was interesting to note that there had 
been statistically significant association between all those factors (except gender) and CHD. The literature supports these findings and shows that there are significant differences in the occurrence of CHD among SGA [62, 63], multiple births [64];, LBW [65], or preterm birth $[63,66,67]$. Multiple birth status potentially affects intrauterine growth and carries a higher risk of premature birth [68]. The mechanism behind why these groups carries a higher risk of having an infant with CHD is not clear. These groups are important to be aware of as they may need to be considered in the implementation of any preventative policy in relation to CHD. Given that some babies are more at risk of having CHD than others, considering these categories is essential to facilitate early detection (via appropriate diagnostic procedures) and appropriate intervention. From a clinical perspective, many CHDs are not diagnosed antenatally and are identified at birth or shortly thereafter. Early diagnosis is important in providing an opportunity for early treatment and the prevention of disabilities and death [69], therefore assessing risk factors and clinical decision making are critical factors to be taken into consideration when formulating CHD policies. This study showed no significant association between gender and CHD, and the literature on gender has shown conflicting results regarding its association with CHD [43, 70].

It is also crucial to comment on the finding that antidiabetic medication prescription during pregnancy is associated with CHD. This finding is highly significant as it suggests that putting women who have DM at the heart of any preventative policy for CHD may be useful. This result aligns with the current literature, which has shown positive association between pre-existing diabetes and CHD [61,71-74]. The possible causal mechanism for this positive association is poorly understood but the main hypothesis clarifying the positive association between maternal DM and CHD in offspring is that a teratogenic effect on the developing heart may be caused by excess glucose [75]. Excess glucose may lead to epigenetic changes that would affect gene expression in the developing embryo [76].

The control of blood glucose in pregnancy could be one of the preventative measures for the development of CHD [77]. Blood glucose control requires regular blood check, diet control, exercise, and subsequent diabetic medication adjustment. Antidiabetic medication prescribed in this study included oral hypoglycaemic medication which may lack efficiency to overcome insulin resistance in pregnancies [78] and hence does not control for blood glucose level. According to the American Diabetes Association guidelines, diabetic women taking oral hypoglycemic medication might be at risk of treatment failure and they should switch to insulin when they are pregnant [79]. It should also be mentioned that there is a signal in the literature which showed that oral hypoglycemic medication such as metaformin might be associated with increased risk of CHD [80]. In addition, although women were prescribed antidiabetic medication, its prescription in this study might not reflect usage of antidiabetic medications (or any other medications) and literature has shown that there is discontinuation of oral antidiabetic medicines during pregnancy among large number of pregnant women [81, 82].

Most of the study covariates did have $0 \%$ missing values, and a few of them showed less than $4 \%$ missing values, which gives credibility to the study results (Table 1 ). The study provides an overview of the profile of pregnant women in NI which is useful for researchers. For example, it showed that $65 \%$ of pregnant women in NI live in urban areas, $15.6 \%$ smoke, and $64.7 \%$ have a planned pregnancy.

It should be noted that the livebirth prevalence of CHD in this data is higher than others in Europe. This may be due to complete ascertainment of both early and later diagnosed cases in the paediatric cardiology database used in this study as well as the fact that during the study period NI was one of the few European countries where termination of pregnancy for fetal anomaly was illegal.

\section{Strengths and limitations}

This is the first population based study to use big data from linked administrative and clinical databases that cover the entire population in NI during the period 20102014 to identify risk factors for CHD, with a large sample size of 94,067 pregnancies and 1162 CHD cases. Different risk factors for developing CHD related to maternal sociodemographic characteristics, behaviours and birth outcomes were assessed and the study was able to adjust for several significant covariates. CHD diagnoses in this study were obtained from RBHSC which is the only centre in NI in which cases are examined by echocardiograph and diagnosed by paediatric cardiologists. Two studies using UK data reported good positive predictive values for ICD-10 codes (PPVs $\geq 90 \%$ ) [83, 84]. There was high ascertainment for CHD diagnosis, all HSD cases underwent echocardiography by paediatric cardiologists using the same echo machines and following the same diagnostic criteria, thereby limiting the chance of case misclassification. Most of the study covariates have a low percentage of missing values which suggests that the data used is high quality. The study provides an overview of the profile of pregnant women in NI which is useful for researchers.

Recall bias has been avoided in this study by using prospectively collected data, as recall bias is expected when 
exposure data is collected retrospectively [85]. Retrospectively collected data with questionnaires may also involve interviewer bias which is also avoided in this study. However, linkage between CHD cases from HSD to NIMATS was not able to link $10.9 \%$ of the CHD cases and the exclusion of those cases from the analysis may have led to under-ascertainment of exposures or outcomes, and might have led to selection bias. Women who moved later in pregnancy and gave birth in NI are all included in the study, however there is no data on women and their births outcome for those who gave birth outside NI during the study period.

However, the study results are as precise as possible using available data and rigid inclusion and exclusion criteria and specifying the importance of the first trimester in highlighting any temporal relationship between potential risk and outcome, which would need to be considered in any future discussion of causation. Caution should be taken when applying the results of this study to other populations due to differences between populations, study period, and methodologies.

It should be noted that this an association rather than causation study, in future studies causation might be assessed more robustly inferred by the introduction of graphical models based on Directed Acyclic Graph (DAG) and using an epidemiological framework such as Bradford-Hill criteria to assess possible cause and effect.

The risk for CHD measured in this study is based on live birth estimates and no estimation was calculated based on stillbirths and termination of pregnancy, and this is one of the study limitations. Ideally, all foetuses with stillbirths and termination of pregnancy including termination of pregnancy for foetal anomalies (TOPFA) should be included, specifying those who have CHD. TOPFA could not be included as TOPFA was not permitted in NI unless: "a woman's life is at risk or where there is a risk of a serious and adverse long term or permanent effect on her physical or mental health" [86].

Although accurate information about TOPFA in NI is not available, reports covering the period 2010-2014 have shown that some pregnant women travelled from NI to England, Scotland or Wales to have an abortion, including TOPFA. There were 4652 abortions performed in England and Wales on women who had travelled from NI during the period 2010-2014 [87]. It is not known how many of those cases have CHD but exclusion of these cases from the analysis may have affected the results. Stillbirths were not included in the study as HSD and NIMATS do not include information about stillbirth cases which are diagnosed as CHD (This practice requires post-mortem for all stillbirths, and this was not the practice in NI during the study period). However, excluding stillbirths from the current study would be expected to have a minimal effect as stillbirth occurs in approximately 264 pregnancies which represents $0.27 \%$ of all pregnancies in this study, and congenital abnormalities including CHD account for only $12-14 \%$ of stillbirths $[88,89]$. The study estimation does not consider pregnancies which end in miscarriage or ectopic pregnancy. The ectopic pregnancy rate in the UK is 11 per 1000 [90] and 1 out of 4 pregnancies ends with miscarriage [91]. However, it is not common practice to include them in studies as it is difficult to identify the cause of miscarriage or whether the foetus in an ectopic pregnancy had a heart problem or not.

There is always a possibility of exposure misclassification in relation to a number of risk factors assessed in this study. For example, pregnant women tend to underestimate their smoking behaviour when self-reporting [92]. Moreover, the study did not examine the factors which may affect total smoking exposure such as environmental tobacco smoke. Future research using serum cotinine measurement to validate smoking risk will give more accurate information regarding the association between smoking in pregnancy and CHD.

Residual confounding by confounders such as ethnicity [93], certain environmental exposure [94], method of conception [95], and preeclampsia [96] may still be present, but the association between the potential residual confounders and CHD, must be strong and specific for CHD to have the potential to alter the findings of this study. In this study, several risks were assessed simultaneously leading to multiple testing issues and potential chance findings. No adjustment was made for multiple testing in this study as doing so may cause significant clinical associations to be lost. This approach has been adopted in other studies [12,97].

Confounding by indication is one of the most important limitations of this study, in which individuals who were exposed to drugs may have experienced a contrary outcome (i.e. CHD) because they are more ill than others. Whether or not the pregnant women took the drugs as prescribed is not confirmed, as redemption of prescription does not necessarily indicate the medication was taken. There is therefore a risk of exposure misclassification, possibly leading to drug use overestimation. This has been considered in the study design in which the exposure period goes back to only one month before LMP in line with the literature which suggested that: "prescriptions given in the period prior to 1 month before the LMP would have resulted in a greater percentage of women who do not use medication during pregnancy" [98]. 


\section{Conclusion}

The study provides data on the maternal sociodemographic characteristics, behaviours and birth outcomes as risk factors for CHD in NI during the period 2010-2014, which is important for public health policy, maternity service providers, researchers, clinicians, and the public.

The identified association and possible causation should be understood and discussed on logical plausibility, and within the overall context of the available evidence to promote CHD prevention. Potential risk factors which did not show positive significant association with CHD in this study should always be understood within the same context. The study has strengths but it has limitations which may also need to be addressed in future studies which involve linking big databases. Other risk factors which are not found in the study data and hence were not assessed should be assessed in future studies.

\section{Acknowledgements}

We would like to acknowledge the original $\mathrm{PhD}$ research supervisory team at Ulster University, Professor Helen Dolk, Dr. Karen Casson, Dr. Maria Loane, Dr. Paul Slater, and Dr. Nichola McCullough. I also would like to acknowledge Dr. Frank Casey and Mrs. Rita Butler from Royal Belfast Hospital for Sick Children.

The authors would like to acknowledge the help provided by the staff of the Honest Broker Service (HBS) within the Business Services Organisation Northern Ireland (BSO). The HBS is funded by the BSO and the Department of Health (DoH). The authors alone are responsible for the interpretation of the data and any views or opinions presented are solely those of the author and do not necessarily represent those of the BSO.

\section{Authors' contributions}

Dr. Hafi Saad: Manuscript writing, literature review, study design, and data analysis. Prof Marlene Sinclair: Manuscript review/edit. Prof Brendan Bunting: Manuscript review/edit and results validation. All authors read and approved the final manuscript.

\section{Funding}

The study was funded by Vice-Chancellor's Research Scholarship Ulster University. Northern Ireland Chest Heart and Stroke covered the costs of data preparation carried out by HBS.

\section{Availability of data and materials}

The data that support the findings of this study are included at aggregate level in this manuscript. Individual data were available/accessed in an anonymised format in the safe haven in HBS under license for the current study. Due to the fact that individuals could be identified from a combination of variables, restrictions apply to the availability of these data publicly. For any query/request about this data please contact Dr. Hafi Saad (H-saad@uster.ac. uk).

\section{Declarations}

\section{Ethics approval and consent to participate}

The study/methods/data collection and analysis were carried out in accordance with relevant guidelines and regulations mainly Declaration of Helsinki, Good Clinical Practice guidelines, General Data Protection Regulation, and Data Protection Act.

Ethical approval including consent waiver was granted from the Institute of Nursing and Health Research Governance Filter Committee, Ulster University (22 June 2015) and from National Health Service (NHS) Research Ethics Committee (NHS-REC) (No. 17/SC/0103, 27 February 2017). Honest Broker Governance Board approval was granted on 2 March 2017.

\section{Consent for publication}

This study is based on anonymised secondary data and no identifiable or individual data are published.

\section{Competing interests}

No competing interests for any authors.

\section{Author details}

${ }^{1}$ Maternal Fetal and Infant Research Centre, Ulster University, Jordanstown, UK.

${ }^{2}$ School of Psychology, Ulster University, Coleraine, UK.

Received: 24 March 2021 Accepted: 19 October 2021

Published online: 10 November 2021

\section{References}

1. Henk G, Katelijne B, Anna P, Judith R, Anke R, Martin H, et al. Stillbirth and neonatal mortality in pregnancies complicated by major congenital anomalies: Findings from a large European cohort. Prenat Diagn. 2017;37:1100-11.

2. Centers for Disease Control and Prevention (CDC). Hospital stays, hospital charges, and in-hospital deaths among infants with selected birth defects--United States, 2003. MMWR Morb Mortal Wkly Rep. 2007;56:25-9.

3. Dadvand P, Rankin J, Shirley MDF, Rushton S, Pless-Mulloli T. Descriptive epidemiology of congenital heart disease in Northern England. Paediatr Perinat Epidemiol. 2009;23:58-65.

4. Gilboa SM, Salemi JL, Nembhard WN, Fixler DE, Correa A. Mortality resulting from congenital heart disease among children and adults in the United States, 1999 to 2006. Circulation. 2010;122:2254-63.

5. Dodge I. New Congenital Heart Disease Review [Internet]. NHS England; 2015 p. 27. Available from: https://www.england.nhs.uk/wp-content/ uploads/2015/07/Item-4-CHD-Report.pdf

6. Becky GMR, Prouhet PM, Russell CL, Pfannenstiel BR. Quality of Life for Parents of Children With Congenital Heart Defect: A Systematic Review. J Cardiovasc Nurs. 2018;33:363.

7. Marino BS, Lipkin PH, Newburger JW, Peacock G, Gerdes M, Gaynor JW, et al. Neurodevelopmental outcomes in children with congenital heart disease: evaluation and management: a scientific statement from the American Heart Association. Circulation. 2012;126:1143-72.

8. Feng Y, Yu D, Yang L, Da M, Wang Z, Lin Y, et al. Maternal lifestyle factors in pregnancy and congenital heart defects in offspring: review of the current evidence. Ital J Pediatr. 2014;40:85.

9. Patel SS, Burns TL. Nongenetic Risk Factors and Congenital Heart Defects. Pediatr Cardiol. 2013;34:1535-55.

10. Business Services Organisation. 2015. Honest Broker Service. Available from: http://www.hscbusiness.hscni.net/services/2454.htm. [Accessed 3 January 2015].

11. Saad H, Bunting B, Mc CJ. How can Big Data be used to answer public health research questions? Evid Based Midwifery. 2021;19(1):19-31.

12. EUROCAT Guide 1.4. 2013. Available from: http://www.eurocat-network. eu/content/Full\%20Guide\%201\%204\%20version\%2021_June2018.pdf. [Accessed 10 December 2015].

13. Furu K, Kieler H, Haglund B, Engeland A, Selmer R, Stephansson O, et al. Selective serotonin reuptake inhibitors and venlafaxine in early pregnancy and risk of birth defects: population based cohort study and sibling design. BMJ. 2015;350:h1798.

14. Crider KS, Cleves MA, Reefhuis J, Berry RJ, Hobbs CA, Hu DJ. Antibacterial medication use during pregnancy and risk of birth defects: National Birth Defects Prevention Study. Arch Pediatr Adolesc Med. 2009;163:978-85.

15. Kornum JB, Nielsen R. B., Pedersen L., Mortensen P. B., Norgaard M. Use of selective serotonin-reuptake inhibitors during early pregnancy and risk of congenital malformations: Updated analysis. Clin Epidemiol. 2010;2:29-36.

16. Knudsen TM, Hansen AV, Garne E, Andersen AM. Increased risk of severe congenital heart defects in offspring exposed to selective serotoninreuptake inhibitors in early pregnancy-an epidemiological study using validated EUROCAT data. BMC Pregnancy Childbirth. 2014;14(1):1-8.

17. Szumilas M. Explaining Odds Ratios. J Can Acad Child Adolesc Psychiatry. 2010;19:227-9. 
18. Gordis L. Epidemiology, Fourth edition. Saunders; 2008. p. 208. https:// www.pdf-archive.com/2014/09/16/leon-gordis-epidemiology-4th-uploa dedby-arif-sobhan/. Accessed 30 Jan 2017.

19. Ranganathan P, Aggarwal R, Pramesh CS. Common pitfalls in statistical analysis: Odds versus risk. Perspect Clin Res. 2015;6(4):222

20. Rothman KJ, Greenland S, Lash TL. Modern Epidemiology. Third ed. Philadelphia, USA: Lipincott Williams and Wilkins; 2008.

21. EBCOG Scientific Committee. The public health importance of antenatal care. Facts Views Vision ObGyn. 2015;7(1):5.

22. Wu L, Li B, Xia J, Ji C, Liang Z, Ma Y, et al. Prevalence of congenital heart defect in Guangdong province, 2008-2012. BMC Public Health. 2014;14:152.

23. Zen TD, Rosa RFM, Zen PRG, Trevisan P, da Silva AP, Ricachinevsky CP, et al. Gestational and family risk factors for carriers of congenital heart defects in southern Brazil. Pediatr Int. 2011;53:551-7.

24. Yu D, Feng Y, Yang L, Da M, Fan C, Wang S, et al. Maternal Socioeconomic Status and the Risk of Congenital Heart Defects in Offspring: A MetaAnalysis of 33 Studies. 2014;

25. Feng $Y, Y u$ D, Chen T, Liu J, Tong $X$, Yang L, et al. Maternal parity and the risk of congenital heart defects in offspring: a dose-response meta-analysis of epidemiological observational studies. PLoS One. 2014;9:e108944.

26. Reefhuis J, Honein MA. Maternal age and non-chromosomal birth defects, Atlanta-1968-2000: Teenager or thirty-something, who is at risk? Birth Defects Res Part A Clin Mol Teratol. 2004;70:572-9.

27. Miller A, Tiffany R, Csaba S, Frías Jaime L, Adolfo C. Maternal age and prevalence of isolated congenital heart defects in an urban area of the United States. Am J Med Genet A. 2011:155:2137-45.

28. Best KE, Rankin J. Is advanced maternal age a risk factor for congenital heart disease? Birth Defects Res Part A Clin MolTeratol. 2016;106:461-7.

29. Malik S, Cleves MA, Honein MA, Romitti PA, Botto LD, Yang S, et al. Maternal smoking and congenital heart defects. Pediatrics. 2008;121:e810-6.

30. Lee LJ, Lupo PJ. Maternal Smoking During Pregnancy and the Risk of Congenital Heart Defects in Offspring: A Systematic Review and Metaanalysis. Pediatr Cardiol. 2013;34:398-407.

31. Alverson CJ, Strickland MJ, Gilboa SM, Correa A. Maternal smoking and congenital heart defects in the Baltimore-Washington Infant Study. Pediatrics. 2011;127:e647-53.

32. van Rooij IALM, Wegerif MJM, Roelofs HMJ, Peters WHM, Kuijpers-Jagtman A-M, Zielhuis GA, et al. Smoking, Genetic Polymorphisms in Biotransformation Enzymes, and Nonsyndromic Oral Clefting: A Gene-Environment Interaction. Epidemiology. 2001;12:502-7.

33. Lupo PJ, Langlois PH, Reefhuis J, Lawson CC, Symanski E, Desrosiers TA, et al. Maternal Occupational Exposure to Polycyclic Aromatic Hydrocarbons: Effects on Gastroschisis among Offspring in the National Birth Defects Prevention Study. Environ Health Perspect. 2012;120:910-5.

34. Barbieri O, Ognio E, Rossi O, Astigiano S, Rossi L. Embryotoxicity of Benzo(a)pyrene and Some of Its Synthetic Derivatives in Swiss Mice. Cancer Res. 1986;46:94-8.

35. Karunamuni G, Gu S, Doughman YQ, Peterson LM, Mai K, McHale Q, et al. Ethanol exposure alters early cardiac function in the looping heart: a mechanism for congenital heart defects? Am J Physiol Heart Circ Physiol. 2014;306:H414-21.

36. Wen Z, Yu D, Zhang W, Fan C, Hu L, Feng Y, et al. Association between alcohol consumption during pregnancy and risks of congenital heart defects in offspring: meta-analysis of epidemiological observational studies. Ital J Pediatr. 2016;42:12

37. Yang J, Qiu H, Qu P, Zhang R, Zeng L, Yan H. Prenatal Alcohol Exposure and Congenital Heart Defects: A Meta-Analysis. PLoS One. 2015;10:e0130681.

38. Feng Y, Wang S, Zhao L, Yu D, Hu L, Mo X. Maternal reproductive history and the risk of congenital heart defects in offspring: a systematic review and meta-analysis. Pediatr Cardiol. 2015;36:253-63.

39. Sullins DP. Abortion, substance abuse and mental health in early adulthood: Thirteen-year longitudinal evidence from the United States: SAGE Open Medicine. London, England: SAGE PublicationsSage UK; 2016. Available from: https://journals.sagepub.com/doi/10.1177/2050312116665997 [Accessed 3 June 2019]

40. Zhu JL, Olsen J, Sørensen HT, Li J, Nohr EA, Obel C, et al. Prenatal Maternal Bereavement and Congenital Heart Defects in Offspring: A RegistryBased Study. Pediatrics Am Acad Pediatrics. 2013;131:e1225-30.
41. Li H, Luo M, Zheng J, Luo J, Zeng R, Feng N, et al. An artificial neural network prediction model of congenital heart disease based on risk factors. Medicine (Baltimore). 2017;96 Available from: https://www.ncbi.nlm.nih. gov/pmc/articles/PMC5313026/. [cited 2020 Jun 3].

42. Ferencz C. Genetic and environmental risk factors of major cardiovascular malformations: the Baltimore-Washington Infant Study, 1981-1989: Futura Publishing Company; 1997.

43. Fung A, Manlhiot C, Naik S, Rosenberg H, Smythe J, Lougheed J, Mondal T, Chitayat D, McCrindle BW, Mital S. Impact of prenatal risk factors on congenital heart disease in the current era. J Am Heart Assoc. 2013;2(3):e000064.

44. Hernández-Díaz S, Werler MM, Walker AM, Mitchell AA. Folic acid antagonists during pregnancy and the risk of birth defects. N Engl J Med. 2000;343:1608-14.

45. Matok I, Gorodischer R, Koren G, Landau D, Wiznitzer A, Levy A. Exposure to folic acid antagonists during the first trimester of pregnancy and the risk of major malformations. Br J Clin Pharmacol. 2009;68:956-62.

46. Meijer WM, De Walle HE, Kerstjens-Frederikse WS. Folic acid sensitive birth defects in association with intrauterine exposure to folic acid antagonists. Reprod Toxicol. 2005;20:203-7.

47. Tierney BJ, Ho T, Reedy MV, Brauer PR. Homocysteine inhibits cardiac neural crest cell formation and morphogenesis in vivo. Dev Dyn. 2004;229:63-73.

48. Boot MJ, Steegers-Theunissen RPM, Poelmann RE, Van Iperen L, Lindemans J, Gittenberger-de Groot AC. Folic acid and homocysteine affect neural crest and neuroepithelial cell outgrowth and differentiation in vitro. Dev Dyn. 2003;227:301-8.

49. Wild J, Sutcliffe M, Schorah CJ, Levene MI. Prevention of neural-tube defects. Lancet. 1997;350:30-1.

50. van Beynum IM, Kapusta L, den Heijer M, Vermeulen SHHM, Kouwenberg M, Daniëls O, et al. Maternal MTHFR $677 \mathrm{C}>$ T is a risk factor for congenital heart defects: effect modification by periconceptional folate supplementation. Eur Heart J. 2006;27:981-7.

51. Tang LS, Wlodarczyk BJ, Santillano DR, Miranda RC, Finnell RH. Developmental consequences of abnormal folate transport during murine heart morphogenesis. Birth Defects Res Part A Clin Mol Teratol. 2004;70:449-58.

52. Wellings K, Jones KG, Mercer CH, Tanton C, Clifton S, Datta J, et al. The prevalence of unplanned pregnancy and associated factors in Britain: findings from the third National Survey of Sexual Attitudes and Lifestyles (Natsal-3). Lancet. 2013;382:1807-16.

53. Mohllajee AP, Curtis KM, Morrow B, Marchbanks PA. Pregnancy Intention and Its Relationship to Birth and Maternal Outcomes. Obstet Gynecol. 2007;109:678

54. Feng Y, Wang S, Chen R, Tong X, Wu Z, Mo X. Maternal folic acid supplementation and the risk of congenital heart defects in offspring: a metaanalysis of epidemiological observational studies. Sci Rep. 2015;5(1):1-8.

55. Hobbs CA, Cleves MA, Melnyk S, Zhao W, James SJ. Congenital heart defects and abnormal maternal biomarkers of methionine and homocysteine metabolism. Am J Clin Nutr. 2005;81:147-53.

56. Werler MM, Hayes C, Louik C, Shapiro S, Mitchell AA. Multivitamin supplementation and risk of birth defects. Am J Epidemiol. 1999:150:675-82.

57. Bower C, Miller M, Payne J, Serna P. Folate intake and the primary prevention of non-neural birth defects. Aust N Z J Public Health. 2006:30:258-61.

58. Stothard KJ, Tennant PW, Bell R, Rankin J. Maternal overweight and obesity and the risk of congenital anomalies: a systematic review and meta-analysis. JAMA. 2009;301:636-50.

59. Mills JL, Troendle J, Conley MR, Carter T, Druschel CM. Maternal obesity and congenital heart defects: a population-based study. Am J Clin Nutr. 2010;91:1543-9.

60. Cai G, Sun X, Zhang L, Hong Q. Association between maternal body mass index and congenital heart defects in offspring: a systematic review. Obstet Gynecol. 2014;211:91-117.

61. Garne E, Loane M, Dolk H, Barisic I, Addor M-C, Arriola L, et al. Spectrum of congenital anomalies in pregnancies with pregestational diabetes. Birth Defects Res Part A Clin MolTeratol. 2012;94:134-40.

62. Malik S, Cleves MA, Zhao W, Correa A, Hobbs CA. Association Between Congenital Heart Defects and Small for Gestational Age. Pediatrics. 2007;119:e976-82.

63. Giorgione V, Fesslova V, Boveri S, Candiani M, Khalil A, Cavoretto P. Adverse perinatal outcome and placental abnormalities in pregnancies with 
major fetal congenital heart defects: A retrospective case-control study. Prenat Diagn. 2020;40(11):1390-7.

64. Best KE, Rankin J. Increased risk of congenital heart disease in twins in the North of England between 1998 and 2010. Heart. 2015;101:1807-12.

65. Petrossian RA, Kuehl KS, Loffredo CA. Relationship of birth weight with congenital cardiovascular malformations in a population-based study. Cardiol Young. 2015;25:1086-92.

66. Tanner K, Sabrine N, Wren C. Cardiovascular malformations among preterm infants. Pediatrics. 2005;116:e833-8.

67. Laas E, Lelong N, Thieulin A-C, Houyel L, Bonnet D, Ancel P-Y, et al. Preterm birth and congenital heart defects: a population-based study. Pediatrics. 2012;130:e829-37.

68. Dudenhausen JW, Maier RF. Perinatal Problems in Multiple Births. Dtsch Arztebl Int. 2010;107:663-8.

69. Olney RS, Ailes EC, Sontag MK. Detection of critical congenital heart defects: Review of contributions from prenatal and newborn screening. Semin Perinatol. 2015;39:230-7.

70. Amel-Shahbaz S, Behjati-Ardakani M, Namayandeh SM, Vafaeenasab M, Andishmand A, Moghimi S, et al. The epidemiological aspects of congenital heart disease in central and southern district of Iran. Adv Biomed Res. 2014;3 Available from: https://www.ncbi.nlm.nih.gov/pmc/articles/ PMC4260289/ [Accessed 2 September 2016].

71. Loffredo CA, Wilson PD, Ferencz C. Maternal diabetes: an independent risk factor for major cardiovascular malformations with increased mortality of affected infants. Teratology. 2001;64:98-106.

72. Correa A, Gilboa SM, Besser LM, Botto LD, Moore CA, Hobbs CA, et al. Diabetes mellitus and birth defects. Obstet Gynecol. 2008;199:237 e1-237. e9.

73. Øyen N, Diaz L, Leirgul E, Boyd HA, Priest J, Mathiesen ER, et al. Prepregnancy Diabetes and Offspring Risk of Congenital Heart Disease. Circulation. 2016;133:2243-53.

74. Chen L, Yang T, Chen L, Wang L, Wang T, Zhao L, et al. Risk of congenital heart defects in offspring exposed to maternal diabetes mellitus: an updated systematic review and meta-analysis. Arch Gynecol Obstet. 2019:300(6):1491-506.

75. Cousins L. Etiology and prevention of congenital anomalies among infants of overt diabetic women. Clin Obstet Gynecol. 1991;34:481-93.

76. Salbaum JM, Kappen C. Diabetic embryopathy: a role for the epigenome? Birth Defects Res Part A Clin Mol Teratol. 2011;91:770-80.

77. Ludvigsson JF, Neovius M, Söderling J, Gudbjörnsdottir S, Svensson AM, Franzén S, Stephansson O, Pasternak B. Periconception glycaemic control in women with type 1 diabetes and risk of major birth defects: population based cohort study in Sweden. BMJ. 2018;362.

78. Alexopoulos AS, Blair R, Peters AL. Management of Preexisting Diabetes in Pregnancy: A Review. JAMA. 2019;321(18):1811-9.

79. American Diabetes A. 14. Management of Diabetes in Pregnancy: Standards of Medical Care in Diabetes-2019. Diabetes Care. 2019;42(Suppl 1):S165-72.

80. Given JE, Loane M, Garne E, Addor MC, Bakker M, Bertaut-Nativel B, et al. Metformin exposure in first trimester of pregnancy and risk of all or specific congenital anomalies: exploratory case-control study. BMJ. 2018;25:361.

81. Charlton RA, Klungsøyr K, Neville AJ, Jordan S, Pierini A, de Jong-van den Berg LTW, et al. Prescribing of Antidiabetic Medicines before, during and after Pregnancy: A Study in Seven European Regions. PLoS One. 2016;11(5):e0155737 4.

82. Lawrence JM, Andrade SE, Avalos LA, Beaton SJ, Chiu VY, Davis RL. Prevalence, trends and patterns of use of antidiabetic medications among pregnant women 2001-2007. Obstet Gynecol. 2013;121(1):106-14. 23262 934.

83. Hammad TA, Margulis AV, Ding Y, Strazzeri MM, Epperly H. Determining the predictive value of Read codes to identify congenital cardiac malformations in the UK Clinical Practice Research Datalink. Pharmacoepidemiol Drug Saf. 2013;22(11):1233-8.

84. Wurst KE, Ephross SA, Loehr J, Clark DW, Guess HA. The utility of the general practice research database to examine selected congenital heart defects: a validation study. Pharmacoepidemiol Drug Saf. 2007;16(8):867-77.

85. Csáky-Szunyogh M, Vereczkey A, Kósa Z, Gerencsér B, Czeizel AE. Risk Factors in the Origin of Congenital Left-Ventricular Outflow-Tract Obstruction Defects of the Heart: A Population-Based Case-Control Study. PediatrCardiol. 2014;35:108-20.

86. Department of Health, Social Services and Public Safety. 2016. Available from: https://www.health-ni.gov.uk/sites/default/files/publications/ dhssps/guidance-termination-pregnancy.pdf. [Accessed 3 January 2016].

87. Torney K. Belfast based journalism project. The Irish Times 2015. Available from: https://www.irishtimes.com/news/health/nearly-25-000-irishwomen-went-to-britain-for-abortions-in-2010-2014-1.2465367. [Accessed 25 July 2016].

88. Stillbirth Collaborative Research Network Writing Group. Causes of death among stillbirths. Jama. 2011;306(22):2459.

89. Scottish Perinatal and Infant Mortality and Morbidity Report. Healthcare Improvement Scotland; 2013. Available from: https://www.isdscotland. org/Health-Topics/Maternity-and-Births/Publications/2013-03-26/201303-26-SPIMMR2011-report.pdf?207155943. Accessed 29 June 2019.

90. Royal College of Obstetricians and Gynaecologists. Diagnosis and Management of Ectopic Pregnancy. Royal College of Obstetricians \& Gynaecologists. 2018. Available from: https://www.rcog.org.uk/en/guide lines-research-services/guidelines/gtg21/ [Accessed 13 Mar 2018].

91. Tommy's. 2018. Available from: https://www.tommys.org/our-organ isation/charity-research/pregnancy-statistics/miscarriage. [Accessed 1 December 2018].

92. Shipton D, Tappin DM, Vadiveloo T, Crossley JA, Aitken DA, Chalmers J. Reliability of self reported smoking status by pregnant women for estimating smoking prevalence: a retrospective, cross sectional study. BMJ. 2009;339:b4347.

93. Knowles RL, Ridout D, Crowe S, Bull C, Wray J, Tregay J, et al. Ethnic and socioeconomic variation in incidence of congenital heart defects. Arch Dis Child. 2017;102(6):496-502.

94. Hu CY, Huang K, Fang Y, Yang XJ, Ding K, Jiang W, et al. Maternal air pollution exposure and congenital heart defects in offspring: a systematic review and meta-analysis. Chemosphere. 2020;253:126668.

95. Giorgione V, Parazzini F, Fesslova VL, Cipriani SO, Candiani M, Inversetti AN, et al. Congenital heart defects in IVF/ICSI pregnancy: systematic review and meta-analysis. Ultrasound Obstet Gynecol. 2018;51(1):33-42.

96. Boyd HA, Basit S, Behrens I, Leirgul E, Bundgaard H, Wohlfahrt J, et al. Association between fetal congenital heart defects and maternal risk of hypertensive disorders of pregnancy in the same pregnancy and across pregnancies. Circulation. 2017;136(1):39-48.

97. Csaky-Szunyogh M, Vereczkey A, Kosa Z, Gerencser B, Czeizel AE. Risk and protective factors in the origin of conotruncal defects of heart-a population-based case-control study. Am J Med GeneticsPart A. 2013;161:2444-52.

98. Källén B, Nilsson E, Olausson PO. Antidepressant use during pregnancy: comparison of data obtained from a prescription register and from antenatal care records. Eur J Clin Pharmacol. 2011;67:839-45.

\section{Publisher's Note}

Springer Nature remains neutral with regard to jurisdictional claims in published maps and institutional affiliations. 